\title{
A wind resource assessment method for floating deep offshore wind turbines
}

\author{
Ana Estanqueiro, António Couto, Luis Rodrigues Jr., and Raquel Marujo \\ Laboratório Nacional de Energia e Geologia \\ Unidade de Análise Energética e Redes \\ Lisbon, Portugal \\ ana.estanqueiro@lneg.pt
}

\begin{abstract}
This paper presents a new methodology for the assessment of the wind energy resource at deep offshore locations where the use of floating wind turbines is foreseen. The wind resource assessment methodology developed follows the principles used by IEC 61400-12-1 standard in general and proposes the use of experimental data from a floating LIDAR on a deep offshore region - that assumes the role of the temporary mast - and a coastal meteorological mast installed onshore acting as the permanent met mast. The methodology takes into consideration the time lag between the locations of the two measurement points and the wind direction associated with different atmospheric phenomena.

The results obtained allow concluding that the methodology increases the accuracy of the wind resource assessment campaign while reducing the involved costs and technical risks. An added advantage is the possibility of extending this methodology for the evaluation of the power performance of floating wind turbines during the operational phase of the power plant.
\end{abstract}

Keywords - Wind resource assessment; Deep offshore; floating wind turbines; Site Calibration; Power Performance. 